\title{
Synthesis and Spectroscopic Characterization of Metal Complexes of Rosuvastatin
}

\author{
Arman Tabassum ${ }^{1 *}$, Muhammad Saeed Arayne ${ }^{1}$ and Najma Sultana ${ }^{2}$ \\ ${ }^{1}$ Department of Chemistry, University of Karachi, Karachi, 75270, Pakistan. \\ ${ }^{2}$ Department of Pharmaceutical Chemistry, Research Institute of Pharmaceutical Sciences, University of Karachi, 75270, \\ Karachi, PAKISTAN.
}

\begin{abstract}
Context: Rosuvastatin is a cholesterol lowering drug. It belongs to class statin. It is prescribed to the patients of coronary artery disease; atherosclerosis; thrombosis; increased low-density-lipoprotein; lipid and triglyceride. Aims:It is a newer drug in market and studies over the pharmacodynamics and pharmacokinetics are in progress. Statin therapy is a long term treatment for which its behavior in the presence of other agents is necessary. For this purpose present study is based on the interaction of the drug with essential and trace elements present in human body or co-administered during multivitamin therapy. Settings and Design: Complexes of rosuvastatin with $\mathrm{Cd}(\mathrm{II}), \mathrm{Cr}$ (II), $\mathrm{Mn}(\mathrm{II}), \mathrm{Fe}(\mathrm{III}), \mathrm{Co}(\mathrm{II}), \mathrm{Ni}$ (II) and $\mathrm{Zn}$ (II) i.e., metals commonly present in multivitamins, were synthesized in laboratory. Methanolic solution of rosuvastatin with metal chloride salts was reacted. Methods and Material: Reaction between drug and metals was carried out in thermostat at $80{ }^{\circ} \mathrm{C}$ for five hours with timely TLC monitoring for completion of reaction. These newly synthesized complexes were identified by IR and NMR spectroscopy and $\mathrm{CHN}$ elemental microanalysis and the structure of complexes was proposed. Results: Analyses suggest two molecules of rosuvastatin co-ordinate with the central metal atom through their carboxylic group. CS Chem3D ultra suggests square planner structure of the complex. Conclusions: Synthesis of compounds proposes that rosuvastatin can bind to metals as ligand through its pharmocophore site that may lead to reduced activity of drug and metal both. The study is precursor to in vitro and in vivo study of interaction of drug and metals.
\end{abstract}

Key words: Rosuvastatin, Statin, IR, NMR, Titration, Metal complex.

\section{INTRODUCTION}

Biosynthesis of cholesterol is a natural phenomenon and gets completed in lever in 25 steps. ${ }^{1,2}$ Disorder in any of the steps may cause over or under production of cholesterol that may lead ultimately to atherosclerosis, thrombosis or coronary artery disease, depending on disorder. ${ }^{3,4}$ Statins are the class of drugs that inhibit HMG CoA reductase, a rate limiting enzyme, competitively during mevalonate pathway in the synthesis of cholesterol in hepatocytes. Rosuvastatin is a synthetic drug of this class. ${ }^{5}$ It is newer drug with $20 \%$ bioavailability $^{6,7}$ and 19 hours elimination half-life. ${ }^{8}$ Like other statins it principally reduces total cholesterol (in hypercholesterolemia), LDL cholesterol (in hyperlipoproteinemia), triglycerides (in hypertriglyceridemia), lipids (in dyslipidemia) and increases HDL cholesterol (in hypolipoprteinemia) ${ }^{9}$ to cure atherosclerosis, thrombosis ${ }^{3}$ and coronary artery disease. ${ }^{4}$

Long term statin therapy usually needs co-administration of different classes of drugs ${ }^{10}$ and multivitamins that include essential and trace elements. ${ }^{11,9}$ Most often the combination of drugs inside body may either increase or reduce the efficacy of either drug or themselves; or may cause any side effects; or may be support-
Submission Date: 16-10-2016; Revision Date: 25-11-2016; Accepted Date: 27-11-2016

DOI: 10.5530/ijper.51.1.14

Correspondence:

Arman Tabassum,

Department of Chemistry, University of Karachi, 75270 , Pakistan.

Phone no: +92 3333223628 E-mail: arman_tabassum@ hotmail.com

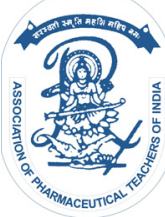

www.ijper.org 
ive in any other activity. Itraconazole increases peak plasma concentration of rosuvastatin when taken simultaneously. ${ }^{12}$ Gemfibrozil affects the pharmacodynamics activity of rosuvastatin. ${ }^{13,14}$ It in combination with digoxin may cause rhabdomyolysis ${ }^{15,16}$ while supporting anticoagulant effect of warfarin is seen with rosuvastatin. ${ }^{17}$ Studies carried out by Edwin and co-workers in 2015 reported decrease in trace elements level in CAD patients. ${ }^{18}$ These metals in the presence of chelating agents may cause chelation and complexation instead of working at the targeting site ${ }^{19}$ and may reduce their or drug's efficacy. Still there is no such study present that may expose the utilization of metals or rosuvastatin other than target site, when taken in combination. Hence synthesis and characterization of new metal complexes with rosuvastatin becomes important for understanding drug-metal ion interaction and their potential pharmacological use. Synthesis and characterization of metal complexes of rosuvastatin have been reported here.

\section{MATERIALS AND METHODS}

Following instruments were used throughout the experiment:

UV-Visible double beam spectrophotometer 1800 (Shimadzu, Japan); FT-IR spectrophotometer Prestige-21 200 VCE (Shimadzu, Japan), ${ }^{1}$ H NMR (Bruker) AMX $300 \mathrm{MHz}$ spectrometer using TMS as an internal standard; LabPro $^{\mathrm{TM}}$ conductometer (Vernier, Oregon); CHN microanalyser (Carlo Erba 1106); melting point apparatus (Gallenkamp, England), electrical balance Libror AEG-120 (Shimadzu, Japan); pH meter (Jenway, UK) and ground glass distillation assembly (Quick fit) (Redleys discovery techniques, UK).

\section{Chemicals and reagents}

Rosuvastatin was provided by the courtesy of Pharm Evo Pvt. Ltd., Karachi, Pakistan. All chemicals and reagents of analytical grade were purchased from Sigma Aldrich (Germany) and Merck (Germany).

\section{Mole ratio determination}

Conductometric titration was carried out using metal chlorides solutions of $1 \mathrm{mM}$ and titrated with $1 \mathrm{mM}$ rosuvastatin ligand at $25^{\circ} \mathrm{C}$ to identify the stoichiometric ratio of drug and metals..$^{20,21}$ Drug $(40 \mathrm{~mL})$ was taken into a flask and $2 \mathrm{~mL}$ of metal chloride was added and conductance values were noted until the graph showed chemical equilibrium. Titration curves were plotted between conductance and volume of titrant (metal chloride $)^{22,23}$ (Figure 1). Confirmation of results was

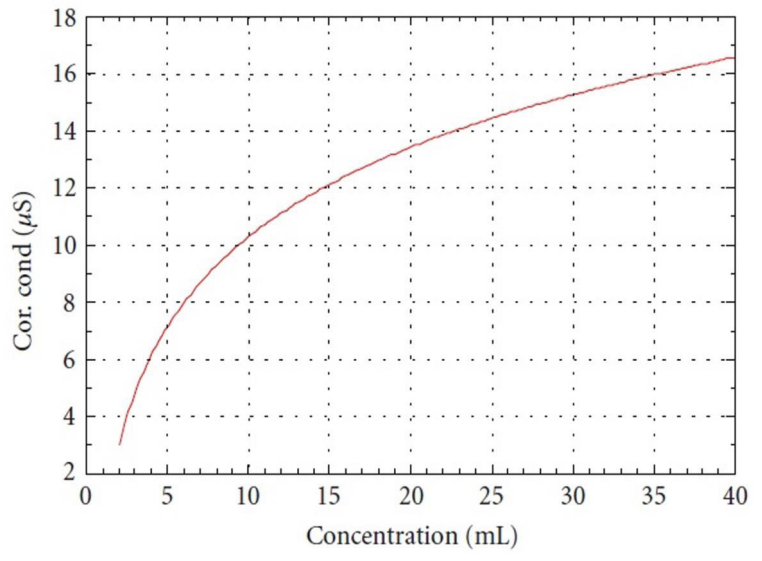

Figure 1: Representative conductometric titration curve of Rosuvastatin and Nickel.

made with job's plot (method of continuous variation) on UV-visible spectrophotometer. ${ }^{22,23}$

\section{Drug-metal reaction}

Syntheses of complexes of rosuvastatin with metal salts were carried out in 1:2 mole ratios of drug and metal. After dissolving calculated mass of reacting species in suitable solvent system, 2-3 drops of orthophosphoric acid was added. The reaction flask was set to reflux for 3 hours at $80^{\circ} \mathrm{C}$. The completion of reaction was confirmed by methanol-chloroform (4:6) TLC system. Solutions were then filtered, evaporated and concentrated under reduced pressure. Precipitates were re-crystallized for purification. Their melting points and physical characteristics were obtained.

\section{Spectral studies of complexes}

Complexes were characterized by FT-IR spectrophotometer in the region of $400-4000 \mathrm{~cm}^{-1}$ using $\mathrm{KBr}$ disk method and ${ }^{1} \mathrm{H}$ NMR. Spectra of NMR were recorded as chemical shift in parts per million relative to TMS as an internal standard in $\mathrm{CDCl}_{3}$ as solvent. Significant ${ }^{1} \mathrm{H}$ NMR data are tabulated in the order of number of protons and multiplicity (s, singlet; d, doublet; t, triplet; $\mathrm{q}$, quartet; and $\mathrm{m}$, multiplet). Molecular modelling was carried out through CS Chem3D Ultra, version 8 (Cambridge Soft Corporation, Cambridge, MA, USA) software.

\section{RESULTS}

Physicochemical and spectroscopic characteristics of rosuvastatin and its complexes have been determined and scheduled in Table 1 and 2 respectively. 


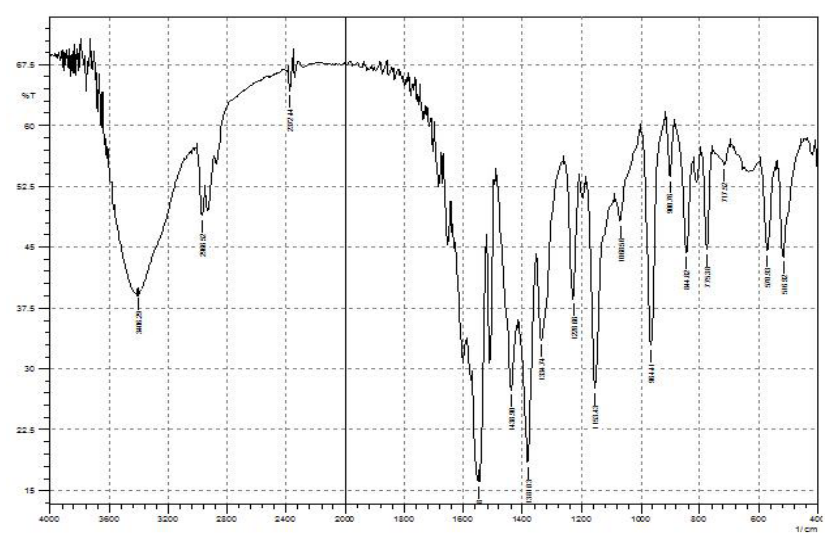

Figure 2a: Representative IR-spectrum of Rosuvastatin.

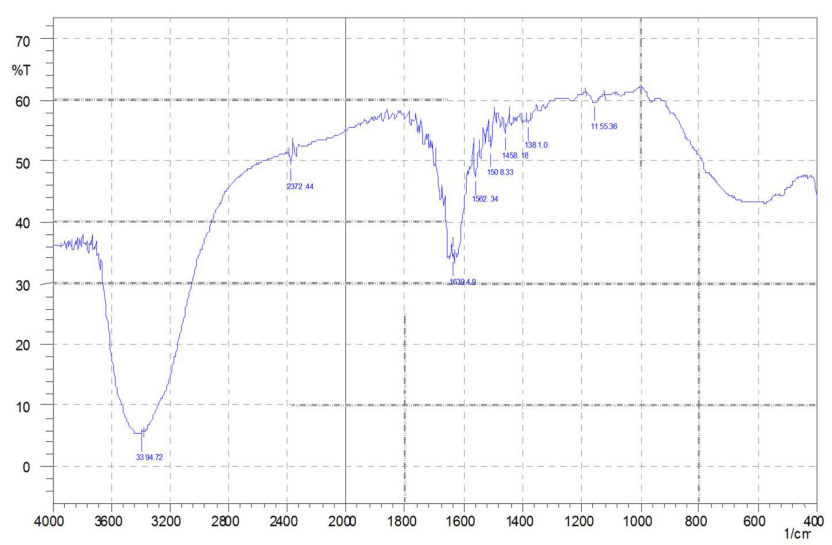

Figure 2b: Representative IR-spectrum of Rosuvastatin-Nickel complex.

\section{Spectroscopic studies of Rosuvastatin-metal complexes}

IR studies: In the IR spectrum of rosuvastatin, there is characteristic broad region of carboxylic $\mathrm{OH}$ at 3625$3200 \mathrm{~cm}^{-1}$ and so carboxylic carbonyl stretch at $1654 \mathrm{~cm}^{-1}$. Asymmetric and symmetric strong stretching vibrations of sulphonamide are seen at 1336 and $1155 \mathrm{~cm}^{-1}$ respectively. Methyl and methylene bending vibrations are present at 1453 and $1438 \mathrm{~cm}^{-1}$. Phenyl $\mathrm{C}=\mathrm{C}$ vibrations are observed at $1511 \mathrm{~cm}^{-1}$. Stretch due to $\mathrm{CF}$ is seen at $1230 \mathrm{~cm}^{-1} \cdot{ }^{24}$ For complexes, all the spectra follow similar regular change in spectrum of rosuvastatin. The band present in rosuvastatin $\left(3625-3200 \mathrm{~cm}^{-1}\right)$ has been slightly shifted or broadened towards lower frequencies. Carbonyl peak is also disturbed and deshaped that corresponds to the bond formation at carboxylic site. (Figure $2 \mathrm{a}$ and $2 \mathrm{~b}$ )

${ }^{1} \mathbf{H}$ NMR studies: Characteristic ${ }^{1} \mathrm{H}$ NMR signals of rosuvastatin in $\mathrm{CDCl}_{3}$ were obtained at $300 \mathrm{MHz}$. The interpretation of signals suggests a peak of chemical

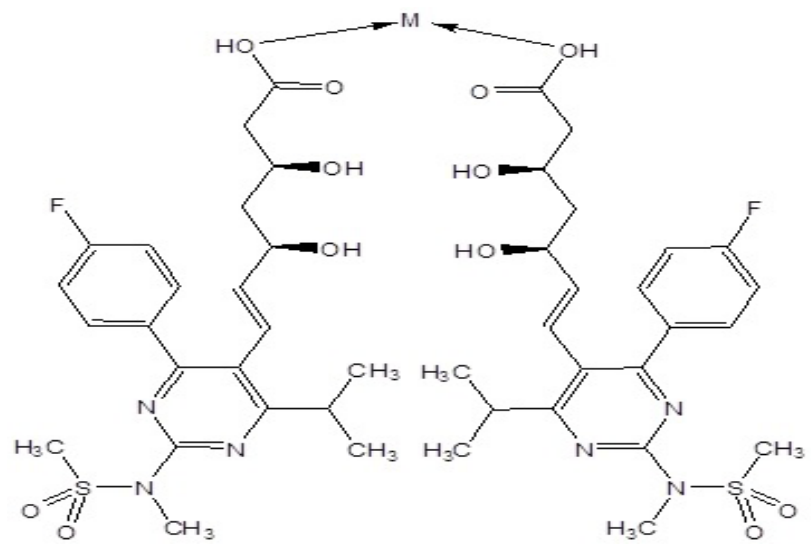

Figure 3: Proposed structure of Rosuvastatin-metal complex where $\mathrm{M}$ refers to $\mathrm{Cd}, \mathrm{Co}, \mathrm{Cr}, \mathrm{Fe}, \mathrm{Mn}, \mathrm{Ni}$ and $\mathrm{Zn}$.

shift at $1.23 \mathrm{ppm}$ for the protons of two methyl groups. Singlet with J value $0.38 \mathrm{~Hz}$ seen at $1.40 \mathrm{ppm}$ is due to aliphatic unsaturated chain. Chemical shifts of 4.32$4.81 \mathrm{ppm}$ are indicative of proton of hydroxyl $\mathrm{OH}$ on aliphatic chain. Signals for ethylene are present at 6.25 and $6.65 \mathrm{ppm}$. Peaks for benzyl are seen at 7.30 and 8.15 ppm. Peaks for protons of carboxylic proton are present at $10.25 \mathrm{ppm}^{25}$.

The metal-complexes in general have similar findings in their spectra. The peak for carboxylic $\mathrm{OH}$ proton is found beyond $10.25 \mathrm{ppm}$ in all spectra of complexes suggesting down fielding effect. The protons of $-\mathrm{CH}_{2}$ adjacent to carboxylic acid group have also been shifted away from TMS. Rest other signals are found at their positions in spectrum of rosuvastatin (Table 4).

CHN elemental microanalysis: The found and calculated percentages of $\mathrm{CHN}$ elemental data are in well agreement with each other and prove the proposed chemical formula of the complex (Table 5, Figure 3).

\section{DISCUSSION}

The long elimination half-life and bioavailability of rosuvastatin expose it as a super-statin (Hamelin, 1998). ${ }^{26}$ From metabolic study of rosuvastatin it is clear that it majorly remains unchanged. ${ }^{1}$ Literature survey reveals that CYP 2C9 enzymes metabolize it very minutely; even then it has shown interaction with some drugs with adverse effects. ${ }^{12}$ Interaction of rosuvastatin is reported with glimepiride (Galani and Vyas, 2010), ${ }^{27}$ clopidogrel $^{28}$ and gemfibrozil. ${ }^{14}$ Warfarin has supporting impact on rosuvastatin. ${ }^{29}$ Erythromycin ${ }^{30}$ and finofibrate ${ }^{31}$ have not shown interaction. Some protease inhibitors also interact with rosuvastatin. ${ }^{32}$ However, prior to this no such study has been reported for the interaction of rosuvastatin with metals (co-administered in the form of multivitamins). 
The structure activity relationship of rosuvastatin suggests that it has a chemical structure consisting variety of electron donating sites responsible for multiple interactions and bonding with its substrate. Deficiency of metals inside body i.e. below their limits lead to reduced physiological functions. It becomes multifaceted to understand the interaction of rosuvastatin with different metals and causes of toxicity onto the body. ${ }^{22,23}$ Accordingly the objective of the present research was to analyse the interaction of rosuvastatin with selected metals for multi-therapy. Since it is prescribed in oral dosage form, there are chances of its interaction at any stage of administration, dissolution, absorption and distribution prior to its target site since metals easily search compounds for chelation or complexation.
The physicochemical study of rosuvastatin suggests that it is very sparingly soluble in water. The drug is soluble in methanol and ethanol. ${ }^{26}$ It shows rapid solubility in chloroform and DMSO. Its stability was checked by melting point (taking twice with the difference of two days. It can withstand as solid at room temperature $\left(25^{\circ} \mathrm{C}\right)$. It absorbs UV radiations at $241-243 \mathrm{~nm}$ due to $\pi-\pi^{*}$ transition between carbonyl oxygen and unsaturated carbon of pyrimidine ring, as a consequence of conjugation of lone pair of nitrogen. ${ }^{33}$

The physicochemical characteristics of the metal-complexes have been scheduled in Table 2. Distinguished properties of these compounds prelude to new complexes formed. The peak at $241 \mathrm{~nm}$ in UV-spectra of the complexes indicates that no change in bonding has taken place at pyrimidine site. The complexes formed

\begin{tabular}{|c|c|c|}
\hline Formula & $\mathrm{C}_{22} \mathrm{H}_{28} \mathrm{FN}_{3} \mathrm{O}_{6} \mathrm{~S}$ & \\
\hline $\begin{array}{l}\text { Molecular } \\
\text { weight }\end{array}$ & $481.538 \mathrm{gmol}^{-1}$ & \\
\hline Melting point & $122^{\circ} \mathrm{C}$ & \\
\hline Solubility & $\begin{array}{c}\mathrm{MeOH}, \mathrm{EtOH}, \mathrm{DMSO}, \\
\text { Chloroform }\end{array}$ & \\
\hline $\begin{array}{c}\text { UV absorbance } \\
(\mathrm{MeOH})\end{array}$ & $241 \mathrm{~nm}$ & \\
\hline $\mathrm{IR}(\mathrm{KBr})$ & \multicolumn{2}{|r|}{ 1155, $1336(\mathrm{O}=\mathrm{S}=\mathrm{O}), 1230(\mathrm{CF}), 1511(\mathrm{C}=\mathrm{C}), 1654(\mathrm{C}=\mathrm{O}), 3625-3200(\mathrm{OH}) \mathrm{cm}^{-1} 24}$. \\
\hline $\begin{array}{l}{ }^{1} \mathrm{H}-\mathrm{NMR} \\
\left(\mathrm{CDCl}_{3}, 300\right. \\
\mathrm{MHz})\end{array}$ & \multicolumn{2}{|c|}{ 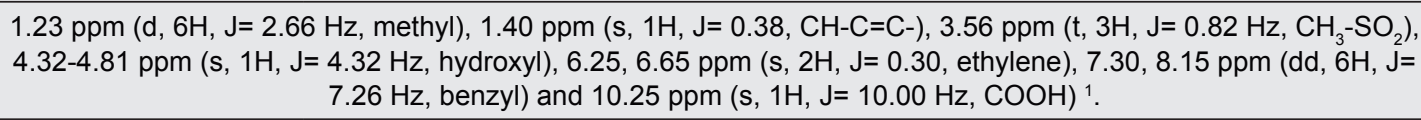 } \\
\hline $\begin{array}{l}\text { Elemental } \\
\text { analysis }\end{array}$ & \multicolumn{2}{|r|}{ C,54.87\%; H,5.86\%; F,3.95\%; N,8.73\%; O,19.94\%; S,6.66\% } \\
\hline
\end{tabular}

\begin{tabular}{|c|c|c|c|c|c|}
\hline \multicolumn{6}{|c|}{ Table 2: Physicochemical parameters of complexes of rosuvastatin with metals } \\
\hline $\begin{array}{c}\text { Complexes with } \\
\text { metals (M) }\end{array}$ & Colour & $\begin{array}{c}\text { Melting } \\
\text { point }\left({ }^{\circ} \text { C) }\right.\end{array}$ & $\begin{array}{c}\text { Mole ratio } \\
\text { Drug: metal }\end{array}$ & $\begin{array}{c}\text { Solubility in } \\
\text { solvents }\end{array}$ & $\%$ Yield \\
\hline Rosuvastatin +Cd & White & 55 & $1: 2$ & MeOH, EtOH & 70 \\
\hline Rosuvastatin +Co & Purple blue & 120 & $1: 2$ & $\mathrm{DMSO}$ & 75 \\
\hline Rosuvastatin +Cr & Grey & 250 & $1: 2$ & $\mathrm{MeOH}$ & 78 \\
\hline Rosuvastatin +Fe & $\begin{array}{c}\text { Brownish } \\
\text { orange }\end{array}$ & 150 & $1: 2$ & $\mathrm{EtOH}$ & 76 \\
\hline Rosuvastatin +Mn & off-white & 65 & $1: 2$ & Water & 65 \\
\hline Rosuvastatin $+\mathrm{Ni}$ & Light green & 180 & $1: 2$ & Water & 75 \\
\hline Rosuvastatin $+\mathrm{Zn}$ & White & 103 & $1: 2$ & $\mathrm{MeOH}$ & 70 \\
\hline
\end{tabular}




\begin{tabular}{|c|c|c|}
\hline \multicolumn{2}{|c|}{$\begin{array}{c}\text { Table 3: Characteristic absorptions of IR spectra of } \\
\text { rosuvastatin-metal complexes }\end{array}$} \\
\hline Complexes & $\begin{array}{c}\boldsymbol{v}(\mathbf{O H}) \text { stretch } \\
\text { cm }^{-1}\end{array}$ & $\boldsymbol{v}\left(\mathbf{C =} \mathbf{O} \mathbf{~ c m ~}^{-1}\right.$ \\
\hline Rosuvastatin & $3625-3200$ & 1654 \\
\hline Rosuvastatin +Cd & $3300-3100$ & 1640 \\
\hline Rosuvastatin +Co & $3400-3100$ & 1631 \\
\hline Rosuvastatin +Cr & $3650-3150$ & 1628 \\
\hline Rosuvastatin +Fe & $3600-3150$ & 1643 \\
\hline Rosuvastatin +Mn & $3600-3100$ & 1628 \\
\hline Rosuvastatin +Ni & $3496-3300$ & 1639 \\
\hline Rosuvastatin + Zn & $3209-3100$ & 1651 \\
\hline
\end{tabular}

\begin{tabular}{|c|c|c|}
\hline \multicolumn{2}{|c|}{$\begin{array}{c}\text { Table 4: Chemical shifts (ppm) in }{ }^{1} \text { H NMR spectra of } \\
\text { rosuvastatin and metal complexes }\end{array}$} \\
\hline $\begin{array}{c}\text { Complexing } \\
\text { metals }\end{array}$ & $\delta\left(\mathbf{C H}_{2}\right) \mathbf{p p m}$ & $\delta(\mathbf{O H}) \mathbf{p p m}$ \\
\hline Rosuvastatin & 3.56 & 10.25 \\
\hline Rosuvastatin +Cd & 0.95 & 10.85 \\
\hline Rosuvastatin +Co & 0.89 & 11.59 \\
\hline Rosuvastatin +Cr & 1.12 & 12.00 \\
\hline Rosuvastatin +Fe & 0.99 & 10.91 \\
\hline Rosuvastatin $+\mathrm{Mn}$ & 0.90 & 11.86 \\
\hline Rosuvastatin $+\mathrm{Ni}$ & 1.34 & 11.44 \\
\hline Rosuvastatin $+\mathrm{Zn}$ & 1.16 & 10.85 \\
\hline
\end{tabular}

\begin{tabular}{|c|c|c|c|c|c|c|c|}
\hline Compound & & $\%$ Carbon & $\%$ Hydrogen & \% Nitrogen & $\%$ Oxygen & $\%$ Sulphur & $\%$ Meta \\
\hline \multirow{2}{*}{ Rosuvastatin } & found & 54.28 & 5.09 & 8.92 & 19.27 & 5.97 & -- \\
\hline & calculated & 54.87 & 5.86 & 8.73 & 19.94 & 6.66 & -- \\
\hline \multirow{2}{*}{ Rosuvastatin + Cd } & found & 50.02 & 5.11 & 7.24 & 17.39 & 6.21 & 09.78 \\
\hline & calculated & 49.14 & 5.25 & 7.81 & 17.85 & 5.96 & 10.45 \\
\hline \multirow{2}{*}{ Rosuvastatin + Co } & found & 51.12 & 5.53 & 8.29 & 18.84 & 6.98 & 4.98 \\
\hline & calculated & 51.71 & 5.52 & 8.22 & 18.79 & 6.27 & 5.77 \\
\hline \multirow{2}{*}{ Rosuvastatin $+\mathrm{Cr}$} & found & 52.56 & 5.87 & 8.90 & 19.31 & 6.62 & 5.09 \\
\hline & calculated & 52.06 & 5.56 & 8.28 & 18.91 & 6.32 & 5.12 \\
\hline \multirow{2}{*}{ Rosuvastatin + Fe } & found & 51.26 & 5.39 & 7.88 & 18.91 & 6.59 & 5.54 \\
\hline & calculated & 51.87 & 5.54 & 8.25 & 18.84 & 6.29 & 5.48 \\
\hline \multirow{2}{*}{ Rosuvastatin $+\mathrm{Mn}$} & found & 51.23 & 5.77 & 8.22 & 18.23 & 6.55 & 5.21 \\
\hline & calculated & 51.91 & 5.54 & 8.26 & 18.86 & 6.30 & 5.40 \\
\hline \multirow{2}{*}{ Rosuvastatin $+\mathrm{Ni}$} & found & 51.38 & 5.99 & 8.15 & 18.02 & 6.73 & 5.57 \\
\hline & calculated & 51.72 & 5.52 & 8.22 & 18.79 & 6.28 & 5.74 \\
\hline \multirow{2}{*}{ Rosuvastatin $+\mathrm{Zn}$} & found & 50.89 & 5.83 & 8.23 & 18.59 & 6.44 & 6.22 \\
\hline & calculated & 51.38 & 5.49 & 8.17 & 18.67 & 6.24 & 6.36 \\
\hline
\end{tabular}

are unstable and cannot withstand at high heat for which their crystallography was not possible.

However the assignments of IR bands were made by comparing the vibrations of complexes with those of the drug. Major absorption bands and frequencies of rosuvastatin (Table 1) and corresponding assignments are discussed below and scheduled in Table 3 .

In metal complexes of rosuvastatin, it is found that the band due to carboxylic $\mathrm{OH}$ has shifted towards lower frequencies or the band has broadened. In spectra of all complexes, there is slight shift in frequencies of carbonyl of carboxylic acid towards lower wave numbers with reduced peak intensity. Deshaping of carbonyl peak at $1639 \mathrm{~cm}^{-1}$ in spectrum of nickel complex of rosuvastatin is seen. Rest of the peaks are undisturbed.
It shows that rosuvastatin has interaction to the metal ion at oxygen of carboxylic $\mathrm{OH}$ site (Table 3).

On comparing the spectra of complexes and drug, all the signals of ${ }^{1} \mathrm{H}$ NMR of free ligand (rosuvastatin) are present in the spectra of complexes except for changes in proton signals of carboxylic group. The downfield shift of these carboxylic protons suggests that they have been deshielded by metal ligand attracted to its oxygen. The signals for phenyl and pyrimidine are unchanged since they are far from binding site of ligand. The resonance of protons of $\mathrm{CH}_{2}(3.56 \mathrm{ppm})$ adjacent to carboxylic acid protons have been shifted downfield due to deshielding effect due to attraction of metal towards carboxylic group in spectra of all complexes. The ${ }^{1} \mathrm{H}$ 
NMR analysis confirms the carboxylic group of rosuvastatin as binding site of metal central atom (Table 4). The CHN elemental analysis (Table 5) supports the IR and ${ }^{1} \mathrm{H}$ NMR analysis. The results are of great importance in elucidating coordination among drug and metals. The very close agreement among the found and calculated values of the elements suggests the chemical formula. Findings suggest that rosuvastatin forms complexes in the ratio 1:2 with all metal ions ${ }^{34}$. Studies suggest that rosuvastatin chelates with the central metal atom through carboxylic oxygen. Two molecules of rosuvastatin coordinate with central metal forming square planner complex. The structure is proposed in Figure 3.

\section{CONCLUSION}

Results from syntheses show that metals and rosuvastatin get engaged by complexation when co-administered. Rosuvastatin can bind to either of the co-administered studied compounds prior to binding to the target enzyme HMG CoA reductase at its heptenoic acid site leaving the drug unavailable to bind with its respective receptors to trigger the action. Occurrence of this event could possibly decrease the clinical efficacy of drug. Hence studies suggest that concomitant use of rosuvastatin and metal salts could pose many side effects in the body and could decrease the efficacy of both. Further synthesis of these new complexes is precursor towards investigation of the in vitro and then in vivo biological evaluation of these compounds.

\section{ACKNOWLEDGEMENT}

The work has been solely accomplished by the financial assistance of the authors.

\section{CONFLICT OF INTEREST}

No conflict of interest are declared.

\section{ABBREVIATION USED}

HMG: Hydroxy Methyl Glutaryl; HDL: High Density Lipoprotein; CAD: Coronary Artery Disease; NMR: Proton Nuclear Magnetic Resonance; CYP: Cytochrome P450.

\section{REFERENCES}

1. Corsini A, Bellosta S, Baetta R, Fumagalli R, Paoletti R and Bernini F. New insights into the pharmacodynamic and pharmacokinetic properties of statins. Pharmacol. Ther. 1999;84(3):413-28. https://doi.org/10.1016/S01637258(99)00045-5

2. Stancu $C$ and Sima A. Statins: Mechanism of action and effects. J. Cell. Mol. Med. 2001;5(4):378-87. https://doi.org/10.1111/j.1582-4934.2001.tb00172.x
PMid:12067471.Vasa M, Fichtlscherer S, Adler K, Aicher A, Martin H, Zeiher AM and Dimmeler S. Increase in circulating endothelial progenitor cells by statin therapy in patients with stable coronary artery disease. Circulation. 2001;103(24):2885-90. https://doi.org/10.1161/hc2401.092816 PMid:11413075.

3. Ray JG, Mamdani M, Tsuyuki RT, Anderson DR, Yeo EL and Laupacis A. Use of statins and the subsequent development of deep vein thrombosis. Arch. Intern. Med. 2001;161(11):1405-10. https://doi.org/10.1001/ archinte.161.11.1405 PMid:11386889.

4. Christians $U$, Jacobsen $W$ and Floren LC. Metabolism and drug interactions of 3-hydroxy-3-methylglutaryl coenzyme A reductase inhibitors in transplant patients: are the statins mechanistically similar? Pharmacol.Ther. 1998;80(1):1-34. https://doi.org/10.1016/s0163-7258(98)00016-3.

5. Pan HY, DeVault AR, Wang ID, Ivashkiv E, Swanson BN and Sugerman AA. Comparative pharmacokinetics and pharmacodynamics of pravastatin and lovastatin. The J. Clin. Pharmacol. 1990;30(12):1128-35. https://doi. org/10.1002/j.1552-4604.1990.tb01856.x PMid:2125605.

6. Pasha M, Muzeeb S, Basha SJS, Shashikumar D, Mullangi R and Srinivas NR. Analysis of five HMG CoA reductase inhibitors, atorvastatin, lovastatin, pravastatin, rosuvastatin and simvastatin: pharmacological, pharmacokinetic and analytical overview and development of a new method for use in pharmaceutical formulations analysis and in vitro metabolism studies. Biomed. Chrom., 2006;20(3):282-93. https://doi.org/10.1002/bmc.561 PMid:16143964.

7. Chapman MJ and McTaggart F. Optimizing the pharmacology of statins: characteristics of rosuvastatin. Atheroscler. Suppl. 2002;2(4):33-7. https:// doi.org/10.1016/S1567-5688(01)00016-2.

8. McTaggart F, Buckett L, Davidson R, Holdgate G, McCormick A, Schneck D, Smith $G$ and Warwick M. Preclinical and clinical pharmacology of rosuvastatin, a new 3-hydroxy-3-methylglutaryl coenzyme A reductase inhibitor. Am. J. Cardiol., 2001;87(5):28-32. https://doi.org/10.1016/S0002-9149(01)01454-0.

9. Bkhaitan MM, Mirza AZ. Stability-indicating HPLC-DAD Method for Simultaneous Determination of Atorvastatin, Irbesartan, and Amlodipine in Bulk and Pharmaceutical Preparations. Bull. Korean Chem. Soc. 2015;36(9):2230-7. https://doi.org/10.1002/bkcs.10433.

10. Curtis T. Drug interactions of medications commonly used in diabetes. Diabetes Spectr. 2006;19(4):202-11. https://doi.org/10.2337/diaspect.19.4.202.

11. Mach F. Statins as immunomodulators. Transp. Immunol. 2002;9(2-4):197-200. https://doi.org/10.1016/S0966-3274(02)00030-8.

12. Bellosta $S$, Paoletti $R$ and Corsini A. Safety of statins focus on clinical pharmacokinetics and drug interactions. Circulation., 2004;109(23):III50-7. https://doi.org/10.1161/01.cir.0000131519.15067.1f.

13. Prueksaritanont T, Tang C, Qiu Y, Mu L, Subramanian R and Lin JH. Effects of fibrates on metabolism of statins in human hepatocytes. Drug Metab. Dispos. 2002;30(11):1280-7. https://doi.org/10.1124/dmd.30.11.1280.

14. Lin JC and Ito MK. A drug interaction between troglitazone and simvastatin. Diabetes Care. 1999;22(12):2104-6. https://doi.org/10.2337/ diacare.22.12.2104a PMid:10587866.

15. Trifir G, Corrao S, Alacqua, M, Moretti S, Tari M, Caputi AP and Arcoraci. V Interaction risk with proton pump inhibitors in general practice: significant disagreement between different drug related information sources. $\mathrm{Br}$. J. Clin. Pharmacol. 2006;62(5):582-90. https://doi.org/10.1111/j.13652125.2006.02687.x PMid:16822281 PMCid:PMC1885178.

16. Simonson SG, Martin PD, Mitchell PD, Lasseter K, Gibson G and Schneck DW. Effect of rosuvastatin on warfarin pharmacodynamics and pharmacokinetics. J. Clin. Pharmacol. 2005;45(8):927-34. https://doi. org/10.1177/0091270005278224 PMid:16027403.

17. Edwin R, Harish BR, Subrahmanyam G, Ramalingam K, Shaik MV. A comparative study of trace element levels in coronary artery tissue of Coronary heart disease patients with serum levels in healthy individuals. International Archives of Integrated Medicine. 2015;2(5):63-71.

18. Flora SJS and Pachauri V. Chelation in Metal Intoxication. Int. J. Eniron. Res. Public Health. 2010;7(7):2745-88. https://doi.org/10.3390/ijerph7072745 PMid:20717537 PMCid:PMC2922724.

19. Prasad S and Guimaraes TLM. Electrometric Investigations on the System Acid-Molybdate and the Formation of Heavy Metal Molybdates. J. Braz. Chem. Soc. 1998;9(3):253-9. https://doi.org/10.1590/S0103-50531998000300009. 
20. Ragab GH and Amin AS. Atomic absorption spectroscopic, conductometric and colorimetric methods for determination of fluoroquinolone antibiotics using ammonium reineckate ion-pair complex formation. Spectrochim. Acta A.Mol. Biomol. Spectrosc. 2004;60(4):973-8. https://doi.org/10.1016/S13861425(03)00327-5

21. Arayne MS, Sultana N, Haroon U and Mesaik MA. Synthesis, characterization, antibacterial and anti-inflammatory activities of enoxacin metal complexes. Bioinorg. Chem. Appl. 2009:1-6. https://doi.org/10.1155/2009/914105 PMid:19657456 PMCid:PMC2719789.

22. Arayne MS, Sultana N, Mirza AZ. Preparation and spectroscopic characterization of metal complexes of gliquidone. J. Mol. Struct. 2009;927(1):54-9. https://doi.org/10.1016/j.molstruc.2009.02.020.

23. Istvan ES and Deisenhofer J. Structural mechanism for statin inhibition of HMG-CoA reductase. Science. 2001;292(5519):1160-4. https://doi. org/10.1126/science.1059344 PMid:11349148.

24. Arayne MS, Sultana N, Tabassum A. In vitro Interaction studies of rosuvastatin and ACE-inhibitors by HPLC, Open J Biochem. 2014;1(2):34-44.

25. Hamelin, BA and Turgeon, J. Hydrophilicity/lipophilicity: relevance for the pharmacology and clinical effects of HMG-CoA reductase inhibitors. Trends in Pharmacological Sciences. 1998;19(1):26-37. https://doi.org/10.1016/ S0165-6147(97)01147-4.n

26. Galani V and Vyas M. In vivo and in vitro drug interactions study of glimepiride with atorvastatin and rosuvastatin. J. Young Pharm., 2010;2(2):196-200. https://doi.org/10.4103/0975-1483.63169 PMid:21264125. PMCid:PMC3021697.

27. Izar MC, Pinheiro L, Franca CN, Barbosa SP, Kasmas SH, Bianco HT, Povoa RM and Fonseca F. Pharmacokinetic interactions between clopidogrel and

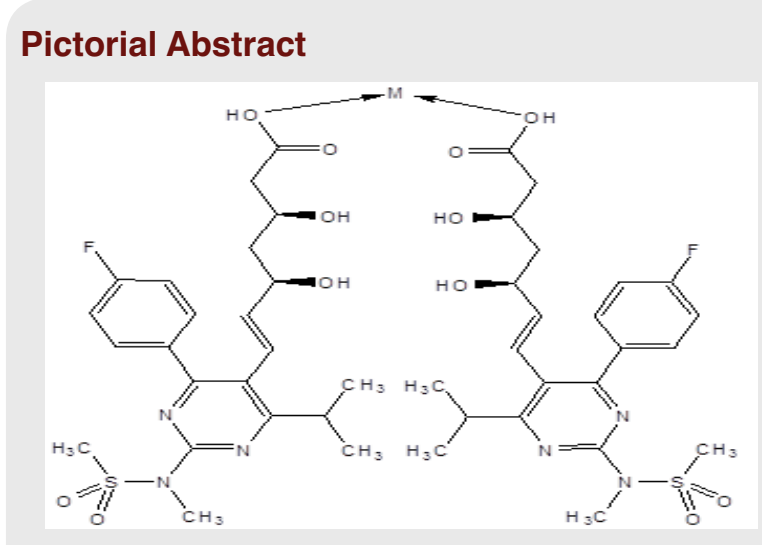

\section{About Authors}

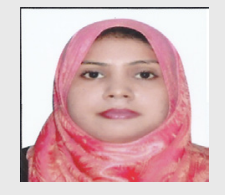

Dr. Arman Tabassum: She is Ph. D. in Chemistry in the field of Pharmaceutical and analytical Chemistry. She is specialized in drug interactions studies, method development on HPLC and Spectroscopy and pharmacological activities. She is currently working on nanoparticle fabrication for efficient drug delivery. She is faculty member in Federal Urdu university of Arts, Science and Technology, Karachi and Preston University, Karachi, Pakistan. rosuvastatin: Effects on vascular protection in subjects with coronary heart disease. J. Am. Coll. Cardiol. 2012;59(13s1):E1538.

28. Simonson SG, Martin PD, Mitchell PD, Lasseter K, Gibson G and Schneck DW. Effect of rosuvastatin on warfarin pharmacodynamics and pharmacokinetics. J. Clin. Pharmacol. 2005;45(8):927-934.

29. Kantola T, Kivist KT and Neuvonen PJ. Erythromycin and verapamil considerably increase serum simvastatin and simvastatin acid concentrations. Clin. Pharmacol. Ther. 1998;64(2):177-182. https://doi.org/10.1016/S00099236(98)90151-5.

30. Ballantyne CM, Davidson MH, Setze CM and Kelly MT. Effects of combination therapy with rosuvastatin and fenofibric acid in patients with mixed dyslipidemia and high-sensitivity C-reactive protein (2 mg/L). J. Clin. Lipidol., 2011;5(5):401-7. https://doi.org/10.1016/j.jacl.2011.06.010 PMid:21981842.

31. Corey, EJ and Zhang, FY. re-and si- Face- selective nitroaldol reactions catalyzed by a rigid chiral quaternary ammonium salt: A highly stereoselective synthesis of the HIV protease inhibitor amprenavir (Vertex 478). Angew. Chem. Int. Ed., 1999;38(13-14):1931-1934.https://doi.org/10.1002/(SICI)1521-3773 (19990712)38:13/14<1931::AID-ANIE1931>3.0.CO;2-4.

32. Alshora DH, Haq N, Alanazi FK, Ibrahim MA, Shakeel F. Solubility of rosuvastatin calcium in different neat solvents at different temperatures. J. Chem. Thermodyn. 2016;94:230-3. https://doi.org/10.1016/j.jct.2015.11.019.

33. Gupta A, Mishra P, and Shah K. Simple UV spectrophotometric determination of rosuvastatin calcium in pure form and in pharmaceutical formulations. Journal of Chemistry. 2009;6(1):89-92. https://doi.org/10.1155/2009/956712.

\section{SUMMARY}

- Cholesterol biosynthesis is a natural phenomenon. When deposition of excess cholesterol in body causes heart related and vascular diseases and disorders, it becomes necessary to reduce the synthesis of cholesterol. Rosuvastatin is a synthetic drug and belongs to class Statins. This class of drugs mimics the activity of HMG Co A Reductase enzyme during cholesterol synthesis in hepatocytes.

- The current project is study over the behaviour of the drug in presence of trace metals co-administered for combination therapy. For this purpose methanolic solution of rosuvastatin was reacted with metal salts at $80 \mathrm{oC}$ for five hours in laboratory. The completion of reaction was monitored by TLC and compound identification was carried out with IR, 1H NMR and elemental analysis. Chemical structure of compounds formed was proposed through CS Chem3D ultra software.

- The studies suggest that the consumption of active site (heptenoic acid side-chain) of drug with metal ions may leave the drug inactive for its actual target and its efficacy may reduce. Vice versa is the case with metal ions present in multivitamins. It is a pre-clinical research. These results prelude to in vitro and then in vivo studies of the drug. 


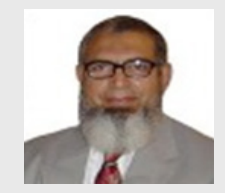

Professor (R) Dr. Muhammad Saeed Arayne: He is the man of substance, progress personified, visionary and an institution in himself. He has been the former Chairman of Department of Chemistry, University of Karachi. He supervised $36 \mathrm{Ph}$.Ds and 43 M.Phils. He is the author of more than 500 international and national journals and conferences, 05 books and 05 patents. He worked for the improvement of curricula in various academic bodies and introduced various graduate and post-graduate courses in chemistry. He also worked for student counseling, guidance and their placement in Pharmaceutical Industry. He is the researcher of versatile nature as his work is seen in electronics, architecture, production of Bio-Diesel

Tissue Culture Technology, plantation of lucrative plants like Ajwa, Jetropha, Sandal and Teak trees in Pakistan.

Professor (R) Dr. Najma Sultana: Has been former Dean and Chairperson of Faculty of Pharmacy and Department of Pharmaceutical Chemistry, University of Karachi respectively. She is former Director of Research Institute of Pharmaceutical Sciences, University of Karachi, Pakistan. She has 40 years of professional experience in research, management and teaching at University level. She has received Presidential award for Science and Technology. She has produced $37 \mathrm{Ph}$.ds and $43 \mathrm{M}$.Phils. She is the author of more than 500 research articles in national and international journals of repute. Her five technologies were granted patents by the Government of Pakistan. She established liaison and professional collaboration with Pharmaceutical Industries and Hospitals related to research and student placement. She has a clear vision of not only to bring universities to highest ranking and standards but also to indigenous needs.

Cite this article: Tabassum A, Arayne MS, Sultana N. Synthesis and Spectroscopic Characterization of Metal Complexes of Rosuvastatin. Indian J of Pharmaceutical Education and Research. 2017;51(1):102-9. 